\title{
Relapse of Major Depression in Women Who Continue or Discontinue Antidepressant Medication During Pregnancy
}

\author{
CONSTANCE GUILLE, M.D., M.S.C.R. and C. NEILL EPPERSON, M.D. \\ Department of Psychiatry and Behavioral Sciences, Medical University of South Carolina, \\ Charleston, and the Department of Psychiatry, Perelman School of Medicine at the University of \\ Pennsylvania, Philadelphia
}

\section{To the Editor}

We applaud Dr. Chaudron's excellent review of the treatment of depression during pregnancy (1) in the January issue. She has provided a wealth of important information that assists clinicians and their patients in making difficult decisions regarding the use of antidepressant medication during pregnancy and the risks of untreated illness. As Dr. Chaudron astutely points out, decision making can span many months preceding pregnancy and into infancy. Given the breadth and scope of issues that can arise during this time, a single review cannot address them all or provide data to guide all decisions. While the focus of the review is the treatment of depression during pregnancy, a common clinical challenge is whether to continue or discontinue antidepressant medication during pregnancy. We felt this was an important area to further elaborate on, given the prevalence of antidepressant use (2) and currently available conflicting data $(3,4)$.

Dr. Chaudron cites an important prospective study by Cohen et al. (3) demonstrating that women with a history of recurrent major depression who discontinued medication during pregnancy or just before conception had five times the risk of another episode of depression compared with women who continued medication during pregnancy. However, in a recent prospective study of pregnant women with a history of depression by Yonkers et al. (4), no differences were found in risk of another episode of depression among women who discontinued antidepressant treatment compared with women who did not. While methodological differences may account for these findings, the conflicting results are likely attributable to divergent populations under investigation. Individuals in the Cohen et al. study were recruited from psychiatric treatment centers and had more severe forms of depression, including early age at onset ( $<14$ years) and comorbid psychiatric illness. Yonkers et al. recruited women from community- and hospital-based obstetric clinics. In both studies, women with at least four previous episodes of depression had a greater risk of relapse of depression during pregnancy, suggesting that those with more severe forms of the disorder are likely at greatest risk for relapse.

Both studies have great clinical importance and can assist clinicians working with women with a history of either severe or mild to moderate major depression. Women with more severe depression that includes early age at onset, psychiatric comorbidity, and at least four previous episodes of depression have a high risk of relapse during pregnancy. Great care and vigilance should be taken to monitor these patients closely, independent of a woman's decision to continue or discontinue medication. The risk of relapse in women with a less severe form of depression or with fewer previous episodes is lower than once estimated.

Dr. Guille reports no financial relationships with commercial interests. 
Data from the Yonkers et al. study can provide reassurance to patients with fewer than four episodes of depression who choose to not take antidepressants during pregnancy.

Dr. Chaudron's review is a must-read for clinicians working with women with depression during pregnancy. We hope we have complemented this review by providing additional data to guide clinicians and their patients in weighing the risks and benefits of antidepressant treatment during pregnancy.

\title{
Acknowledgments
}

Dr. Epperson has received grant support from Shire and Novartis.

\begin{abstract}
Support provided by the NIH Office of Research on Women's Health and National Institute of Child Health and Human Development (K12 HD055885) career development award, Building Interdisciplinary Research Careers in Women's Health.
\end{abstract}

\section{References}

1. Chaudron L. Complex challenges in treating depression during pregnancy. Am J Psychiatry. 2013; 170:12-20. [PubMed: 23288385]

2. Andrade SE, Raebel MA, Brown J, Lane K, Livingston J, Boudreau D, Rolnick SJ, Roblin D, Smith DH, Willy ME, Staffa JA, Platt R. Use of antidepressant medications during pregnancy: a multisite study. Am J Obstet Gynecol. 2008; 198:194e1-194e5. [PubMed: 17905176]

3. Cohen LS, Altshuler LL, Harlow BL, Nonacs R, Newport DJ, Viguera AC, Suri R, Burt VK, Hendrick V, Reminick AM, Loughead A, Vitonis AF, Stowe ZN. Relapse of major depression during pregnancy in women who maintain or discontinue antidepressant treatment. JAMA. 2006; 295:499-507. [PubMed: 16449615]

4. Yonkers KA, Gotman N, Smith MV, Forray A, Belanger K, Brunetto WL, Lin H, Burkman RT, Zelop CM, Lockwood CJ. Does antidepressant use attenuate the risk of a major depressive episode in pregnancy? Epidemiology. 2011; 22:848-854. [PubMed: 21900825] 